\title{
The (non)-projective properties of the Japanese counter-expectational intensifier yoppodo
}

\author{
Osamu Sawada*
}

\begin{abstract}
This paper investigates the projective and non-projective properties of the Japanese counter-expectational intensifier yoppodo. Yoppodo has some unique semantic and pragmatic characteristics that ordinary intensifiers do not. In adjectival environments, yoppodo must co-occur with an inferential evidential marker (modal) and infers a high degree via the evidence. It also conventionally implicates that the high degree is above a speaker's expectation. The interesting feature of yoppodo is that its relationship with an evidential marker is tied up in the issue of projectability. If yoppodo is embedded under an attitude predicate and there is an evidential modal in the embedded clause, then yoppodo's counter-expectational meaning is subjectoriented. However, if yoppodo is embedded under an attitude predicate and there is an evidential modal in the main clause, then yoppodo's counter-expectational meaning is speaker-oriented. I argue that the projective property of yoppodo is different from both typical conventional implicatures (e.g., expressives, appositives; see Potts 2005, 2015; Tonhauser et al. 2013) and typical presuppositions, and I claim that it belongs to a new type of projective content, a "dependent projective content." This paper provides a new perspective for the theories and classification of projective content.
\end{abstract}

Keywords. intensifier; co-occurrence with a modal; evidentiality; counterexpectation; conventional implicature; expressive; dependent projective content

1. Introduction. This paper investigates the meaning and the (non)-projective property of the Japanese counter-expectational intensifier yoppodo. Yoppodo has complex semantic and pragmatic characteristics. Observe the following example:

(1) (Context: Taro is looking at a ramen restaurant from the outside. He sees a lot of people waiting in front of the restaurant.)

Ano raamen-ya-wa yoppodo oishii *(-nichigainai).

That ramen-restaurant-TOP YOPPODO delicious-must

At-issue: That ramen restaurant must be very delicious.

Not-at-issue: The degree I inferred via extraordinary evidence is above my expectation.

In (1), the speaker observes that there are many people waiting in front of a ramen restaurant. Based on this evidence, the speaker (semantically) infers a high degree of deliciousness of (the food served at) the ramen restaurant. There is also an expressive/not-at-issue meaning that the degree inferred via extraordinary evidence is above the speaker's expectations. Note that if there is no evidential modal in (1), the sentence becomes ill-formed, suggesting that there is some kind of dependency between yoppodo and nichigainai 'must.'

\footnotetext{
* I am very grateful to Magdalena Kaufmann, Chris Kennedy, Yusuke Kubota, Eric McCready, Harumi Sawada, Jun Sawada, Jérémy Zehr, and the audience of LSA 2016 for their valuable discussions and detailed comments regarding the content of this manuscript. Parts of this paper were also presented at University of Tsukuba, LENLS 2016, and the Semantics Workshop in Tokai (2015), and I also thank those audiences for their valuable comments and suggestions. This paper is based upon work supported by JSPS KAKENHI Grant Number 26770140. All remaining errors are of course my own. Author: Osamu Sawada, Mie University (sawadao@human.mie-u.ac.jp).
} 
What is interesting about yoppodo is that its relationship with an evidential marker is also related to the issue of projectability. In an environment where yoppodo is embedded under an attitude predicate, whether yoppodo's counter-expectational meaning can project or not depends on the position of an evidential modal. If yoppodo is embedded in the complement of an attitude predicate and there is an evidential modal in the embedded clause, then the not-at-issue meaning triggered by yoppodo is always anchored to the subject of the sentence (here Taro):

(2) (Context: Taro sees a lot of people waiting in front of the ramen restaurant and thinks that this situation is unusual.)

Taro-wa [ano ramen-ya-wa yoppodo oishii-nichigainai]-to omo-tteiru.

Taro-TOP that ramen-store-TOP YOPPODO delicious-must-that think-TEIRU

At-issue: Taro thinks that the ramen restaurant must be very delicious.

Not-at-issue: The degree Taro inferred via extraordinary evidence is above Taro’s expectation.)

On the other hand, if yoppodo is embedded in the complement of an attitude predicate and there is an evidential modal (a concord element) in the main clause, then yoppodo's not-at-issue meaning is always anchored to the speaker:

(3) (Context: The speaker observes that Taro goes to the ramen restaurant KIKUYA every day.)

Taro-wa [ano ramen-ya-wa yoppodo oishii]-to omo-tteiru-nichigainai.

Taro-TOP that ramen-store-TOP YOPPODO delicious-that think-TEIRU-must

At-issue: Taro must think that that ramen restaurant is very delicious.

Not-at-issue: The degree I inferred via extraordinary evidence is above my expectation.

In this paper I will argue that yoppodo's projective behavior (the asymmetrical behavior shown in (2) and (3)) is fundamentally different from the projective behaviors of typical presuppositions and typical conventional implicatures (CIs), and that yoppodo belongs to a new type of projective content, namely, “dependent.” I will further argue that this dependent projective content has a semantic property that requires consistency between an at-issue meaning and a CI meaning in terms of a judge.

A theoretical implication of this paper is that there can be a "semantic" interaction between projective content and external judge-sensitive expressions (despite the fact that these are logically independent of each other). This paper provides a new perspective on the varieties of projective content.

2. The semantic and pragmatic characteristics of yoppodo. Before investigating the projective behavior of yoppodo, let us first examine the semantic and pragmatic characteristics of yoppodo. As the following example shows, yoppodo is clearly an intensifier. It cannot co-occur with a non-gradable predicate:

(4) * Taro-wa yoppodo gakusei-nichigainai.

Taro-TOP YOPPODO student-must

'Taro must be yoppodo a student.'

However, unlike ordinary intensifiers, yoppodo has complex semantic and pragmatic characteristics: its co-occurrence requirement with an evidential modal and its property of expressive/CI. 
2.1 Co-OCCURRENCE WITH AN EVIDENTIAL MODAL. First, let us discuss the co-occurrence with an evidential modal. As we observed in the Introduction, in an adjectival environment, yoppodo must co-occur with an evidential modal. More specifically, yoppodo must co-occur with a marker that involves an "inferential evidential." Inferential evidentials are those types of evidential where the speaker draws an inference on the basis of available physical evidence (de Haan 2013). ${ }^{1}$ Let us observe some examples:

(5) a. (Context: The speaker is looking at a ramen restaurant from the outside. He sees a lot of people waiting in front of the restaurant.)

$\begin{array}{lll}\text { Ano raamen-ya-wa } & \text { yoppodo } & \text { oishii-nichigainai. } \\ \text { That ramen-store-TOP } & \text { YOPPODO } & \text { delicious-must }\end{array}$

At-issue: That ramen restaurant must be very delicious.

Not-at-issue: The degree I inferred via extraordinary evidence is above my expectation.

b. (Context: The speaker noticed that Hanako is sleeping during class. The speaker knows that Hanako is a very serious student and she never sleeps during class.)

Hanako-wa yoppodo tukare-teiru-no-daroo.

Hanako-TOP YOPPODO tire-TEIRU-NODA-possibly

At-issue: Hanako must be very tired.

Not-at-issue: The degree I inferred via extraordinary evidence is above my expectation.

c. (Context: The speaker saw Taro running away after he saw a very small spider.)

Taro-wa kumo-ga yoppodo kowai-rashii.

Taro-TOP spider-NOM YOPPODO scary-RASHII

At-issue: It seems that Taro is very terrified of a spider.

Not-at-issue: The degree I inferred via extraordinary evidence is above my expectation.

Nichigainai in (5a), no-daroo in (5b), and rashii in (5c) are inferential evidential markers. ${ }^{2}$ In these examples, the speaker infers a high degree based on the unusual evidence and conveys that this degree, inferred via evidence, is counter-expectational. For example, in (5a) the speaker infers a high degree of deliciousness of the ramen restaurant based on the unusual situation (evidence), and also conveys that this degree is above his/her expectation. As we will discuss in detail in the next section, a speaker's unexpected feeling is not at-issue. It is a conventional implicature. Similar inferential reasoning is observed in (5b) and (5c).

The crucial point is that, as Watanabe (1987) also observes, if there is no evidential modal, the sentences become ill-formed. For example, if we delete nichigainai from (5a), the whole sentence becomes ill-formed:

(6) * Ano raamen-ya-wa yoppodo oishii.

That ramen-store-TOP YOPPODO delicious

'That ramen restaurant is yoppodo delicious.'

\footnotetext{
${ }^{1}$ Aikhenvald (2014) considers the inferred evidential (or inferential evidential) to be based on visible or tangible evidence, or results.

${ }^{2}$ Note that rashii also has a hearsay evidential use (McCready and Ogata), but yoppodo cannot be used with a hearsay evidential:

(i) (The speaker heard that Taro is very busy.)

\# Taro-wa yoppodo isogashii-rashii.

Taro-TOP YOPPODO busy-Report

'I heard that Taro is yoppodo busy.'
}

See McCready and Ogata (2007) for the detailed discussion on the various uses of rashii. 
This connection suggests that there is a dependency between yoppodo and evidential modals similar to modal concord (e.g., Geurts and Huitink 2006; Zeijlstra 2008) or "modal matching" (Grosz 2010) in German discourse particles. Grosz (2010) and Kaufmann (2013) claim that German modal particles such as ruhig require a modal similarly to yoppodo, although yoppodo is not a discourse particle. As we will discuss in section 4, in non-adjectival environments such as comparatives and conditionals, yoppodo is not required to co-occur with an inferential evidential marker.

Note that this dependency is not found in typical intensifiers. For example, it is perfectly natural to use totemo in both modal and non-modal environments:

a. Ano raamen-ya-wa totemo oishii. That ramen-store-TOP very delicious

'That ramen restaurant is very delicious.'

b. Ano raamen-ya-wa totemo oishii-nichigainai.

That ramen-store-TOP very delicious-must

'That ramen restaurant must be very delicious.'

Notice also that yoppodo in the adjectival sentence cannot interact with non-evidential modals like kamoshirenai 'may' and daroo 'possibly.' Neither kamoshirenai nor daroo have a inferential evidential component; they thus cannot co-occur with yoppodo, as is clear from (8):

(8) ?? Ano raamen-ya-wa yoppodo oishii-\{kamoshirenai/daroo\}.

That ramen-store-TOP YOPPODO delicious-may/possibly

At-issue: That ramen restaurant may be very delicious.

However, if the particle no is added to kamoshirenai and daroo (i.e., no-kamoshirenai, no-daroo), then (8) becomes natural, as in (9):

$\begin{array}{lll}\text { Ano raamen-ya-wa } & \text { yoppodo } & \text { oishii-no-\{kamoshirenai/daroo }\} \\ \text { That ramen-store-TOP } & \text { YOPPODO } & \text { delicious-NODA-may/possibly }\end{array}$

At-issue: That ramen restaurant may be very delicious.

Not-at-issue: The degree I inferred via extraordinary evidence is above my expectation.

In (9), no-kamoshirenai and no-daroo behave like evidential modals, presumably due to the meaning of the discourse particle no(da) (see H. Sawada 2006).

2.2 THE SPEAKER'S UNEXPECTED FEELING IS A CI. Another important characteristic of yoppodo is that it has an expressive/non-at-issue meaning. Intuitively, the speaker uses yoppodo when he/she is surprised at the situation driving the utterance. In (10), the speaker infers an unexpectedly high degree of deliciousness for the ramen restaurant (i.e., cause) in order to explain the unusual situation (i.e., consequence). Note that inferential evidential markers such as nichigainai infer a cause from a consequence (Rivière (1981); H. Sawada (2001a,b, 2006)):

(10) (Context: Taro is looking at a ramen restaurant from the outside. He sees more than 50 people waiting in front of the restaurant.)

Ano raamen-ya-wa yoppodo oishii-nichigainai.

That ramen-store-TOP YOPPODO delicious-must

At-issue: That ramen restaurant must be very delicious.

Not-at-issue: The degree I inferred via extraordinary evidence is above my expectation.

Here, the speaker observes an utterance situation (with surprise) and infers a cause, trying to explain the situation. 
I would like to define the lexical meaning of yoppodo as follows:

(11) The lexical meaning of yoppodo (in an adjectival environment): semantically, yoppodo denotes high degree and additionally conventionally implicates that the degree a judge infers through extraordinary evidence is above the judge's expectation.

(where a judge is a speaker in non-embedded environment.)

This means that yoppodo (the adjective modifying use) is mixed content (McCready 2010; Gutzmann 2012); it has an intensified meaning at the at-issue level and inferential/counterexpectational meanings at the CI level. The crucial point here is that in order to use yoppodo naturally, the evidence has to be abnormal. If the observed evidence is not abnormal as in (12), the sentence with yoppodo (but not totemo) becomes odd:

(12) (Context: Taro is looking at a ramen restaurant from the outside. He sees some people waiting in front of the restaurant.)

Ano raamen-ya-wa $\{$ ??yoppodo/totemo oishii-nichigainai.

That ramen-store-TOP YOPPODO/very delicious-must

'That ramen restaurant must be $\{$ yoppodo/totemo $\}$ delicious.'

Here, seeing some people waiting outside the restaurant is not something that makes the speaker to infer an abnormally high degree of deliciousness.

Let us now verify that yoppodo has a CI meaning as in (11). In the Gricean approach, CI is considered to be independent of "what is said" (the at-issue meaning) (Grice 1975; Potts 2005; Horn 2007; McCready 2010; Sawada 2010, 2014; Gutzmann 2012). There are several pieces of evidence for the idea that yoppodo's CI meaning, that the inferred degree is unexpected, is a CI. First, it never interacts with logical operators. As the following example shows, the non-at-issue meaning that "the inferred degree is beyond a judge's expectation" is not within the scope of an evidential modal and question. ${ }^{3}$

(13) (Context: Taro is looking at a ramen restaurant from outside. He sees a lot of people waiting in front of the restaurant.)

Ano raamen-ya-wa yoppodo oishii-no-daroo-ka.

That ramen-store-TOP YOPPODO delicious-NODA-possibly-Q

At-issue: Is it the case that ramen restaurant very delicious?

Not-at-issue: The degree I inferred via extraordinary evidence is above my expectation.

The second piece of evidence is that the CI meaning cannot be challenged by a normal objection: "No, that will be false" cannot challenge the CI/not-at-issue component in (14A), supporting the idea that it is independent of "what is said":
A: Ano raamen-ya-wa yoppodo oishii-nichigainai.
That ramen-store-TOP YOPPODO delicious-must
At-issue: That ramen restaurant must be very delicious.
Not-at-issue: The degree I inferred via evidence is above my expectation.

\footnotetext{
${ }^{3}$ Note that negation is not a good test for checking the independence/projective behavior of yoppodo. It is known that an evidential modal cannot be within the scope of negation (e.g., H. Sawada 2006; see also de Haan 1997):

(i) * Ano raamen-ya-wa yoppodo oishii-nichigaina-kunai.

That ramen-restaurant-TOP YOPPODO delicious-must-NEG

'That ramen restaurant must not be yoppodo delicious.'
} 
B: Iya, sore-wa uso-daroo.

No that-TOP false-epistemic

'Well, that will be false.'

Notice that yoppodo has an at-issue meaning of 'very.' This conclusion is supported by the fact that an addressee can challenge the at-issue (intensification) part of (14A) by uttering the sentence in (15):

$$
\begin{aligned}
& \text { Iya, sonnan-demo nai-to omoun-da-kedo } \\
& \text { No such level-DEMO not-that think-PRED-but } \\
& \text { 'Well, I don't think that it is that high ...' }
\end{aligned}
$$

Note that regular intensifiers, like the Japanese totemo 'very,' do not trigger this kind of unexpected meaning, as exemplified in (16): ${ }^{4}$

(16) (Context: Taro is looking at a ramen restaurant from outside. He sees a lot of people waiting in front of the restaurant.)

Ano raamen-ya-wa totemo oishii-nichigainai.

That ramen-store-TOP very delicious-must

At-issue: That ramen restaurant must be very delicious.

The sentence in (16) denotes that the degree of deliciousness of the food served at the ramen restaurant is high, but it does not convey that this degree is unexpected.

Before closing this section, let me mention that yoppodo's not-at-issue meaning is not a presupposition. In the literature, it is assumed that the utterance of a sentence with presupposition $p$ is felicitous only if $p$ is entailed by the context. ${ }^{5}$ For example, the sentence with the presupposition too (e.g., Tom ate sushi, too) is felicitous only if the implication that there is a true alternative proposition (i.e., Someone besides Tom ate sushi) is entailed by the context. Yoppodo does not have this contextual felicity constraint. The non-at-issue meaning that a judge has an unexpected feeling is discourse new and it is not entailed by the context.

3. Formal analysis of the evidential use of yoppodo. How then can these lexical properties be analyzed? I propose that yoppodo (the adjective modifying use) is mixed content (McCready 2010; Gutzmann 2012) and has the meaning like (17). It has an intensified meaning at the atissue level (the left side of $\bullet$ ) and inferential/counter-expectational meanings at the CI level (the right side of ) (">!!STAND" means "much greater than a standard" (Kennedy and McNally 2005)):

$$
\begin{aligned}
{[[\text { yoppodo }]]=} & \lambda G \lambda x \lambda t \lambda w \exists d[d>! ! \text { STAND } \wedge \mathrm{G}(d)(x)(t)(w)] \bullet j \text { infers the given } d \text { via ex } \\
& \text { traordinary evidence } \wedge d>d, \\
& \text { (where } w \text { is bound by an evidential modal, } j \text { is a judge [either a speaker or } \\
& \text { a subject] and } d \text { ' is a speaker's degree of expectation) }
\end{aligned}
$$

In the at-issue component yoppodo semantically denotes that the degree associated with a gradable predicate is much greater than the contextual standard at the at-issue level. In the CI component, yoppodo conventionally implies that the given degree inferred via evidence is above

\footnotetext{
${ }^{4}$ Notice, however, that there is also an expressive/CI use of totemo, which intensifies the unlikelihood/impossibility of a given proposition (Sawada 2014).

${ }^{5}$ Tonhauser et al. (2013) call this a strong contextual felicity constraint.
} 
the judge's expectation. The CI component requires that there be an evidential modal in the sentence. Otherwise, the sentence violates the constraint and it becomes ill-formed.

Let us consider the logical structure of sentences with yoppodo, since yoppodo is mixed content. To ensure that the meaning of mixed content is computed in a compositional fashion, following McCready (2010), I assume the following compositional rule for mixed content, which involve(s) the shunting type $s$ :

(18)

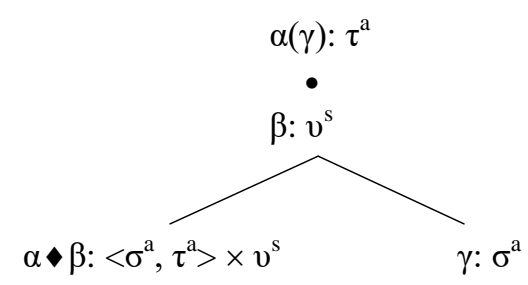

(Based on McCready 2010: 20)

Yoppodo and an adjective are combined via the above role. Regarding the meaning of gradable predicates, I assume that they represent relationships between individuals and degrees (Seuren 1973; Cresswell 1976; von Stechow 1984; Klein 1991; Kennedy 2007):

(19) [[ooshii]]: $<d^{a},<e^{a},<i^{a},<s^{a}, t^{a}>>>>$

$$
=\lambda d \lambda x \lambda t \lambda w \text {.delicious }(x)(t)(w)=\mathrm{d}
$$

As for the meaning of nichigainai, I assume the following meaning: ${ }^{6}$

(20) [[nichigainai] $\left.]^{w, g}=\lambda p<s^{a}, t^{a}\right\rangle . \forall w^{\prime}$ compatible with the evidence in $w_{0}: p\left(w^{\prime}\right)=1$ for $j$

The following figure shows the logical structure of the sentence in (14A):

\footnotetext{
${ }^{6}$ There is also a possibility that the evidential component of nichigainai is not-at-issue (CI/presupposition). See, e.g., Portner (2009), von Fintel and Gillies (2010), and McCready (2010) for the discussions on the semantic status of evidentiality.
} 


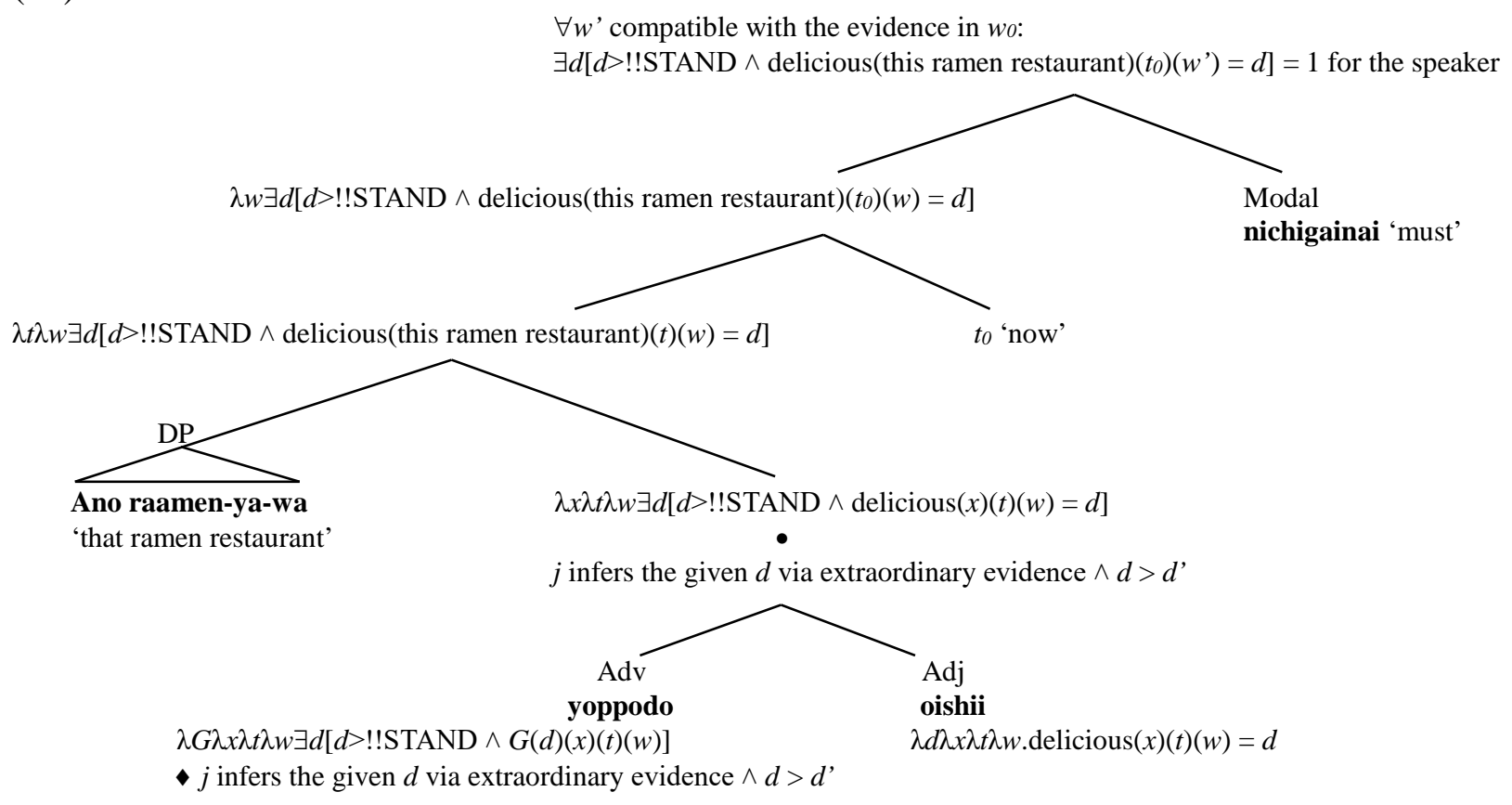

4. Notes on the other uses of yoppodo. In this paper, we have observed that in an adjectival environment yoppodo must co-occur with an evidential modal. An interesting point is that in a nonadjectival environment, this requirement disappears. For example, yoppodo can appear in comparative, conditional, and volitive modal contexts, and in these environments, inferential evidential markers do not arise (see also Watanabe 1987):

(22) [Comparative environment] (Context: It is extremely hot in Tokyo. Since it is extremely hot, it is also impossible to walk outside.)

Okinawa-no hoo-ga (Tokyo-yori) yoppodo suzushii-desu.

Okinawa-GENI direction-NOM Tokyo-than YOPPODO cool-PRED.POL

At-issue: It is much cooler in Okinawa than in Tokyo.

CI: I am making an abnormal ranking based on the extraordinary situation (i.e., it is extremely hot in Tokyo).

(23) [Conditional environment] (Context: The addressee does not study at all despite the fact that the final exam will be held next week.)

Yoppodo isyoukenmei benkyoo si-na-kerenba siken-ni ukara-nai-yo.

YOPPODO hard study do-NEG-COND exam-to pass-NEG-YO

At-issue: You will not be able to pass the exam unless you study very hard.

CI: I am positing an unexpectedly high degree given the unusual situation.

(24) [The environment of volitive modality] (Context: The speaker's boss is always rude to me.

Yoppodo i-tte yar-oo-ka-to omo-tta.

YOPPODO say-TE give-volitive-that think-PAST

At-issue: I had a desire to say a bad word.

CI: I am positing an extraordinary high desire of saying a bad word, but I did not say a bad word.

In (22), the speaker is indirectly conveying that the given utterance situation is abnormal by conveying that Okinawa is much cooler than Tokyo. In (23), the speaker is positing that an 
unexpectedly high degree of effort is necessary in order for the addressee to pass the exam given the current unusual situation (i.e., the addresses has not studied at all.) In (24), yoppodo cooccurs with a volitive modal, emphasizing the speaker's strong willingness to exhibit negative behavior, but at the same time, it conveys that the speaker did not perform the action. In these examples, yoppodo does not co-occur with an evidential modal. In fact, in these environments, evidential modality does not naturally co-occur with an evidential modal. ${ }^{7}$

Although yoppodo has multiple uses, they share an important similarity: in all the examples, yoppodo posits unexpectedly high degree in order to convey that the at-issue situation is abnormal. ${ }^{8}$

5. (Non)-projective property of yoppodo. Let us now consider the context of embedding. The interesting feature of yoppodo is that the relationship with an evidential marker is deeply related to the issue of projectability. That is, whether yoppodo's CI meaning can project out of a complement of an attitude predicate depends on the position of the evidential modal. If yoppodo is embedded under an attitude predicate and there is an evidential modal in the embedded clause, then yoppodo is always subject-oriented:

(25) (Context: Taro sees a lot of people waiting in front of the ramen restaurant and thinks that this situation is unusual.)

Taro-wa [ano ramen-ya-wa yoppodo oishii-nichigainai]-to omo-tteiru.

Taro-TOP that ramen-store-TOP YOPPODO delicious-must-that think-TEIRU

At-issue: Taro thinks that that ramen restaurant must be very delicious.

CI: The degree Taro inferred via extraordinary evidence is above Taro's expectation. (Only the subject-oriented reading is available.)

${ }^{7}$ As the following sentence shows, if we insert nichigainai in the comparative sentence (22), the sentence sounds odd:

(i) ?? Okinawa-no hoo-ga (Tokyo-yori) yoppodo suzushii-nichigainai.

Okinawa-GENI direction-NOM Tokyo-than YOPPODO cool-must

At-issue: It must be the case that Okinawa is much cooler than Tokyo.

CI: I am making an abnormal ranking based on the extraordinary situation (i.e., it is extremely hot in Tokyo).

This sentence sounds odd because it conveys that there is an evidence for the idea that Okinawa is much cooler than Tokyo, but at the same time in the CI component, the speaker says that the ranking is abnormal.

Regarding conditional environments, it is well known that epistemic modality/evidential marker cannot appear in the antecedent of conditional (Palmer 1983: 213; Westney 1995: 57; H. Sawada 2006). As the following sentence shows, if nichigainai is added to (24), the sentence becomes ill-formed:

$\begin{array}{llllll}\text { (ii) * Yoppodo } & \text { isyoukenmei } & \text { benkyoo } & \text { si-teiru-nichigaina-kereba } & \text { siken-ni } & \text { ukara-nai-yo. } \\ \text { YOPPODO } & \text { hard } & \text { study } & \text { do-NEG-COND } & \text { exam-to } & \text { pass-NEG-YO }\end{array}$

'*You will not be able to pass the exam unless you must be studying very hard.'

CI: I am positing an unexpectedly high degree given the unusual situation.

Regarding volitive use, evidential modality cannot be used because volitive modality and evidential modality are semant2ically incompatible.

${ }^{8}$ Note that there is also an expression yoppodo-no koto 'yoppodo-GEN thing'. This expression is always used in the context of 'unless':

(i) Yoppodo-no koto-ga nai-kagiri, watashi-wa gakkou-o yasuma-nai. YOPPODO-GEN thing-NOM NEG-unless I-TOP school-ACC absernt-NEG

'I will not be absent from school unless something unexpected happens.'

Here there is no speaker attitude toward an utterance situation. This use of yoppodo is slightly different from other uses of yoppodo, although it also denotes an unexpectedly high degree. 
The following figure shows the basic structure of (25):

(26)

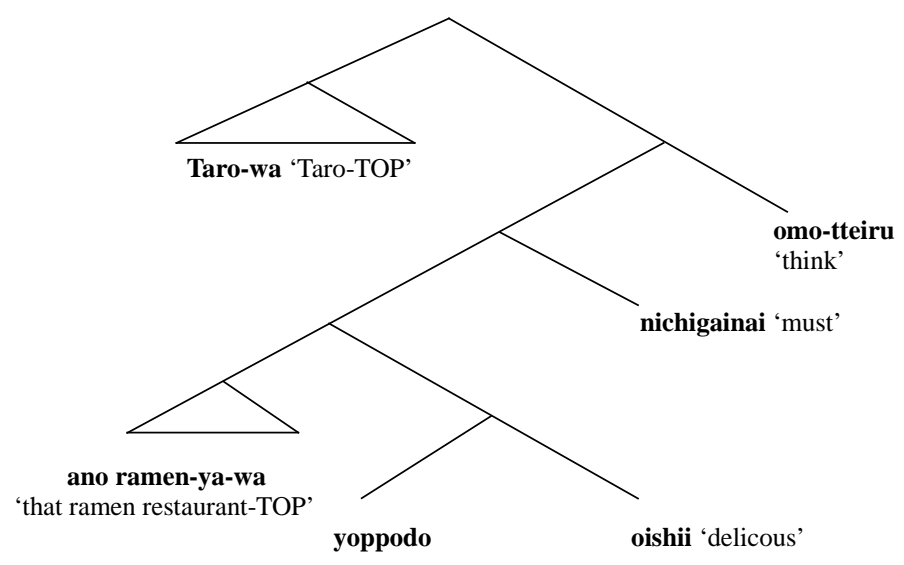

However, if yoppodo is embedded under an attitude predicate and there is an evidential modal (a concord element) in the main clause, then yoppodo is always speaker-oriented:

(Context: The speaker notices that Taro goes to the ramen restaurant KIKUYA every day.) Taro-wa [ano ramen-ya-wa yoppodo oishii]-to omo-tteiru-nichigainai. Taro-TOP that ramen-store-TOP YOPPODO delicious-that think-TEIRU-must At-issue: Taro must think that that ramen restaurant is very delicious.

CI: The degree I inferred via extraordinary evidence is above my expectation. (Only the speaker-oriented reading is available.)

The following figure shows the basic structure of (27):

(28)

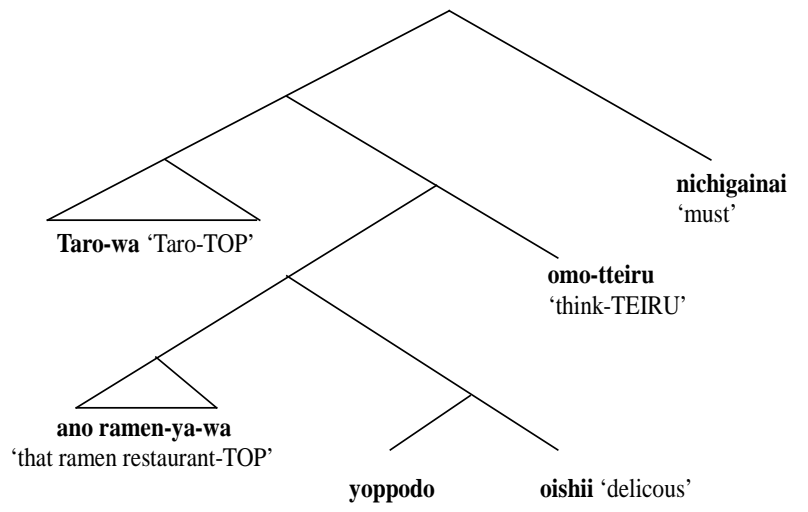

Note that if the modal in the main clause is not an inferential evidential marker, the sentence becomes ill-formed:

(29) (Context: The speaker notices that Taro goes to the ramen restaurant KIKUYA every day.)

* Taro-wa [ano ramen-ya-wa yoppodo oishii]-to omo-tteiru-kamoshirenai.

Taro-TOP that ramen-store-TOP YOPPODO delicious-that think-TEIRU-may

'Taro may think that that ramen restaurant is yoppodo delicious.'

Notice that things are radically different in the case of ordinary intensifiers like totemo. The presence or absence of an evidential modal in the main clause does not change the projection. 
In (30) and (31), totemo is anchored to the subject of the sentences:

(30) (Context: Taro sees a lot of people waiting in front of the ramen restaurant and thinks that this situation is unusual.)

Taro-wa [ano ramen-ya-wa totemo oishii-nichigainai]-to omo-tteiru.

Taro-TOP that ramen-store-TOP very delicious-must-that think-TEIRU

'Taro thinks that that ramen restaurant must be very delicious.'

(Totemo 'very' = subject-oriented)

(31) (Context: The speaker notices that Taro goes to the ramen restaurant KIKUYA every day.) Taro-wa [ano ramen-ya-wa totemo oishii]-to omo-tteiru-nichigainai.

Taro-TOP that ramen-store-TOP very delicious-that think-TEIRU-must

'Taro must think that that ramen restaurant is very delicious.'

(Totemo 'very' = subject-oriented)

The questions then are: why is it that there is no speaker-oriented reading in (25)? Why is it that there is no subject-oriented reading in (27)? I argue that this is because yoppodo lexically requires consistency in judge identity between yoppodo and the evidential modal. In (25), there cannot be a speaker-oriented reading because if such a reading is attempted, a conflict will arise in terms of the judge. In (25), since nichigainai 'must' is embedded under an attitude predicate, the person who evaluates the proposition (based on the evidence) has to be the subject (Taro). The CI component of yoppodo should adjust to the judge because it does not have modal force itself. On the other hand, (27) does not have a subject-oriented reading because nichigainai is located in the main clause. Since yopodo does not have modal force, its judge needs to be the same as the judge of nichigainai.

Notice that if there are two modals in a single sentence, one in the embedded clause and the other in the main clause, in principle, the sentence can be ambiguous between a speakeroriented reading (where the CI meaning of yoppodo is matched with the modality in the main clause) and a subject-oriented reading (where the CI meaning of yoppodo is matched with the modality in the embedded clause):

Taro-wa [ano ramen-ya-wa yoppodo oishii-nichigainai]-to
Taro-TOP that ramen-store-TOP YOPPODO delicious-must-that
omo-tteiru-nichigainai.
think-TEIRU-must
'Taro must think that that ramen restaurant must be yoppodo delicious.'

There may be a preference for yoppodo to interact with the nearest modal, but it seems that it can interact with the modal in the main clause if we posit an appropriate context.

6. A new class of projective content. What does the projective behavior of yoppodo theoretically mean? I argue that the counter-expectational (explanatory) use of the Japanese intensifier yoppodo provides important insight for current theories into the taxonomy of projective content, especially the parametric classification based on "obligatory local effect" (Tonhauser et al. 2013) given in (33):

(33) The parameter of obligatory local effect: A projective content $m$ with trigger $t$ has an obligatory local effect if and only if, when $t$ is syntactically embedded in the complement of a belief-predicate $B, m$ is necessarily part of the content that is targeted by, and within the scope of, $B$ (Tonhauser et al. 2013: 93). 
Under this parameter, typical presupposition triggers, such as stop, will be classified as having an obligatory local effect because their presuppositional implications do not project beyond the belief predicate. For example, the possessive expression in (34a) creates the presupposition that "Sam has a kangaroo," but if (34a) is embedded under the attitude predicate believe, the flow of presupposition is blocked, as shown in (34b):

(34) a. Sam's kangaroo is sick.

(Presuppose: Sam has a kangaroo.)

b. Sue believes that Sam's kangaroo is sick.

(The presupposition "Sam has a kangaroo” does not project.)

The fact that "Sam has a kangaroo" is not projected to the root level is supported by the following sentence:

(35) Sue believes that Sam's kangaroo is sick, but that's ridiculous-Sam doesn't own a kangaroo (Potts 2007b).

Let us now consider the projective property of typical CIs, such as expressives and appositives. Potts (2005) claims that expressives and appositives are CIs:

(36) a. That bastard Kresge should be fired.

(CI: I have a negative feeling toward Kresge.)

b. Sheila believes that Chuck, a psychopath, is fit to watch the kids.

(CI: Chuck is a psychopath.)

Potts furthermore claims that expressives and appositives project, even if they are embedded in the complement of an attitude predicate, such as believe or verbs of saying, which function as a presupposition plug (Karttunen 1973). The fact that (37a) and (37b) are odd support the fact that the expressive bastard and the appositive are anchored to the speaker:

(37) a. Sue believes that that bastard Kresge should be fired. (\#I think he’s a good guy.)

(Potts 2007a: 170)

b. Sheila believes that Chuck, a confirmed psychopath, should be locked up. \# But Chuck isn’t a confirmed psychopath.

(Potts 2005: 117)

However, recent studies have shown that, contrary to Potts' (2005) initial claim, CI expressions such as appositives and expressives can have a non-speaker orientation (e.g., Karttunen and Zaenen (2005); Wang, Reese, and McCready2005; Amaral, Roberts, and Smith (2007); Potts (2007); Sauerland (2007); Haris and Potts (2009)). For example, Amaral et al. (2007) show that the sentences in (38) have a subject-anchored interpretation:

(38) a. (Context: Joan is crazy. She's hallucinating that some geniuses in Silicon Valley have invented a new brain chip that's been installed in her left temporal lobe and permits her to speak any of a number of languages she's never studied.) Joan believes that her chip, which she had installed last month, has a twelve year guarantee. (Amaral et al. (2007), pp. 735f.)

b. (Context: We know that Bob loves to do yard work and is very proud of his lawn, but also that he has a son Monty who hates to do yard chores. So Bob could say (perhaps in response to his partner's suggestion that Monty be asked to mow the lawn while he is away on business): Well, in fact Monty said to me this very morning that he hates to mow the friggin' lawn. (Amaral et al. (2007), pp. 736) 
These examples show that appositives and expressives do not have an obligatory local effect (e.g., Potts 2005, 2007a, 2013; Amaral et al. 2007; Harris and Potts 2009; Tonhauser et al. 2013).

Now let us consider the projective behavior of yoppodo. Although the parameter concerning obligatory local effect in (33) may be useful for distinguishing a typical presupposition trigger (such as stop) from a typical CI expression (such as an appositive or expressive) in terms of projection, it does not seem to capture the difference between typical CIs/presuppositions and yoppodo. The parameter would hold that yoppodo has the property of a non-local effect, but it is difficult to capture the fact that the projection is dependent on the presence of an external element (i.e., the evidential modal). If an evidential marker is inside the complement of an attitude predicate, yoppodo must be obligatorily local, but if there is an evidential modal in the main clause, yoppodo must be obligatorily global. The projective behavior of yoppodo strongly suggests that it is a member of a new class of projective content. This dependent projective content is content that must match with external element in terms of the judge.

7. Conclusion. This paper investigated the meaning and projective properties of the Japanese intensifier yoppodo. I first claimed that unlike regular intensifiers, in the adjectival environment yoppodo must co-occur with an inferential evidential marker. I also argued that yoppodo is mixed content, in that it not only semantically intensifies a degree but also conventionally implicates that the degree inferred via abnormal evidence is above a judge's expectation.

I then showed that the relationship between yoppodo and an evidential marker is deeply related to the issue of projectability. If yoppodo is embedded under an attitude predicate and there is an evidential modal in the embedded clause, then yoppodo's counter-expectational meaning is subject-oriented. However, if yoppodo is embedded under an attitude predicate and there is an evidential modal in the main clause, then yoppodo's counter-expectational meaning is speakeroriented. I argued that yoppodo's projective behavior is different from both typical CIs and typical presupposition, and I claimed that yoppodo belongs to a new type of projective content, a “dependent” projective content.” The dependent projective content requires consistency between an at-issue meaning and a CI meaning in terms of the judge.

The main theoretical implication of this paper is that there can be a "semantic" interaction between projective content and external judge-sensitive expression (despite the fact that they are logically and dimensionally independent of each other). This point is different from appositives and expressives, whose perspective shifting is contextual and pragmatic (Harris and Potts 2010).The phenomenon of yoppodo suggests that there is a variation in the projective behavior of not-at-issue content/CI, and that both pragmatic and semantic factors must be taken into consideration when accounting for the variation.

In a future study, I would like to investigate to what extent the dependent projective content is pervasive. I would also like to consider whether the phenomenon of yoppodo can be treated under a general theory of modal-concord.

\section{References}

Aikhenvald, Alexandra Y. 2004. Evidentiality. Oxford: Oxford University Press.

Amaral, Patricia, Craige Roberts, and Allyn Smith. 2007. Review of the logic of conventional implicatures by Chris Potts. Linguistics and Philosophy 30. 707-749. http://dx.doi.org/10.1007/s10988-008-9025-2.

Cresswell, Max J. 1976. The semantics of degree. In Barbara Partee (ed.), Montague grammar. 261-292. New York: Academic Press. 
de Haan, Ferdinand. 2013. Semantic Distinctions of Evidentiality. In Dryer, Matthew S. \& Haspelmath, Martin (eds.), The world atlas of language structures online. Leipzig: Max Planck Institute for Evolutionary Anthropology.

(Available online at http://wals.info/chapter/77, Accessed on 2016-05-19.)

de Haan, Ferdinand. 1997. The interaction of modality and negation: A typological study. Garland: New York.

Geurts, Bart, and Janneke Huitink. 2006. Modal Concord. In Paul Dekker and Hedde Zeijlstra (eds.), Proceedings of the ESSLLI 2006 workshop concord phenomena at the syntax semantics interface. 15-20. University of Malaga.

Grice, Paul. H. 1975. Logic and conversation. In Peter Cole and Jerry Morgan (eds.), Syntax and semantics, iii: Speech acts. 43-58. New York: Academic Press.

Grosz, Patrick. 2010. Grading Modality: A New Approach to Modal Concord and its Relatives. In M. Prinzhorn, V. Schmitt and S. Zobel (eds.), Proceedings of Sinn und Bedeutung 14. 185-201. Vienna, Austria.

Gutzmann, Daniel. 2012. Use-conditional meaning: Studies in multidimensional semantics. Doctoral dissertation, University of Frankfurt.

Harris, Jesee. A. and Potts, Christopher. 2009. Perspective-shifting with appositives and expressive. Linguistics and Philosophy 32(6). 523-552. http://dx.doi.org/10.1007/s10988-0109070-5.

Horn, Laurence R. 2007. Toward a Fregean pragmatics: Voraussetzung, Nebengedanke, Andeutung. In Istvan Kecskes \& Laurence Horn (eds.), Explorations in pragmatics. 39-69. Berlin: Mouton de Gruyter.

Kaufmann, Magdalena. 2013. Discourse particle 'ruhig': Discourse effects, desires, and modality. Paper Presented at the 3rd Cornell Workshop in Linguistics and Philosophy: Modal Talk and Reasoning.

Karttunen, Lauri. 1973. Presuppositions of compound sentences. Linguistic Inquiry 4(2). 169193.

Karttunen, Lauri and Annie Zaenen. 2005. Veridicity. In G. Katz, J. Pustejovsky, \& F. Schilder (eds.), Annotating, extracting and reasoning about time and events. Dagstuhl Seminar Proceedings 05151. Dagstuhl, Germany.

Kennedy, Christopher. 2007. Vagueness and grammar: the semantics of relative and absolute gradable adjectives. Linguistics and Philosophy 30(1). 1-45.

http://dx.doi.org/10.1007/s10988-006-9008-0.

Kennedy, Christopher, and Louise McNally. 2005. Scale structure, degree modification, and the semantics of gradable predicates. Language 81(2). 345-381.

http://dx.doi.org/10.1353/lan.2005.0071.

Klein, Ewan. 1991. Comparatives. In Arnim von Stechow and Dieter Wunderlich (eds.), Semantik: Ein internationales handbuch der zeitgenossischen forschung, 673-91. Berlin: Walter de Gruyter.

McCready, Eric. 2010. Varieties of conventional implicature: evidence from Japanese. Semantics \& Pragmatics 3. 1-57. http://dx.doi.org/10.3765/sp.3.8.

McCready, Eric and Norry Ogata. 2007. Evidentiality, modality and probability. Linguistics and Philosophy 30. 147-206. http://dx.doi.org/10.1007/s10988-007-9017-7.

Palmer, Frank.R. 1983. Semantic explanations for the syntax of the English modals. In Heny, F.\& Richards, B. (eds.), Linguistic categories: auxiliaries and related puzzles, vol. 2. Dordrecht: Reidel. 205-217. 
Portner, Paul. 2009. Modality. Oxford: Oxford University Press.

Potts, Christopher. 2015. Presupposition and implicature. In Shalom Lappin and Chris Fox, (eds.), The Handbook of contemporary semantic theory (2nd ed). 168-202. Oxford: WileyBlackwell.

Potts, Christopher. 2007a. Into the conventional-implicature dimension. Philosophy Compass 4(2): 665-679. http://dx.doi.org/10.1111/j.1747-9991.2007.00089.x.

Potts, Christopher. 2007b. The expressive dimension. Theoretical Linguistics 33(2). 165-197. http://dx.doi.org/10.1515/TL.2007.011.

Potts, Christopher. 2005. The logic of conventional implicatures. Oxford: Oxford University Press.

Rivière, Claude. 1981. Is should a weaker must? Journal of Linguistics 17. 179195. http://dx.doi.org/10.1017/S0022226700006940.

Sawada, Harumi. 2006. Modaritii (Modality). Kaitakusya: Tokyo.

Sawada, Harumi. 2001a. Ninshiki no patan to houjodoushi no imi kaisyaku 1 (The patterns of recognition and the interpretation of modal auxiliaries, Part 1). Eigo Seinen 147(3). 185-189.

Sawada, Harumi. 2001b. Ninshiki no patan to houjodoushi no imi kaisyakau 2 (The patterns of recognition and the interpretation of modal auxiliaries, Part 2). Eigo Seinen 147(4), 225-229.

Sawada, Osamu. 2014. An utterance situation-based comparison. Linguistics and Philosophy 37(3). 205-248. http://doi.org/10.1007/s10988-014-9150-z.

Sawada, Osamu. 2010. Pragmatic aspects of scalar modifiers. Chicago, IL: University of Chicago dissertation.

Seuren, Peter.A.M. (1973). The comparative. In Ferenc Kiefer and Nicolas Ruwet (eds.), Generative grammar in Europe. 528-64. Dordrecht: Reidel.

Tonhauser, Judith, David Beaver, Craige Roberts, and Mandy Simons. 2013. Toward a taxonomy of projective content. Language 89. 66-109. http://dx.doi.org/10.1353/lan.2013.0001.

von Stechow, Arnim. 1984. Comparing semantic theories of comparison. Journal of Semantics 3: 1-77. http://dx.doi.org/10.1093/jos/3.1-2.1.

von Fintel, Kai, and Anthony S. Gillies. 2010. Must ... stay ... strong! Natural Language Semantics 18. 351-383. http://dx.doi.org/10.1007/s11050-010-9058-2.

Wang, Linton, Brian Reese \& Eric McCready. 2005. The projection problem of nominal appositives. Snippets 10. 13-14.

Watanabe, Minoru. 1987. Hikakufukushi yohodo ni tuite (On the comparative adverb yohodo.) Sophia University, Kokubungakka kiyoo 4. 39-52.

Westney, Paul. 1995. Modals and periphrastics in English. Max Niemeyer Verlag: Tübingen.

Zeijlstra, Hedde. 2008. Modal concord is syntactic agreement. In M. Gibson and T. Friedman (eds.), Proceedings of SALT XVII. Ithaca: CLS Publications. 